\title{
Conceptualisation of e-learning in nursing education in the context of Rwanda
}

\author{
Alexis Harerimana*1,2, Ntombifikile Gloria Mtshali ${ }^{2}$ \\ ${ }^{1}$ James Cook University, Townsville, Australia \\ ${ }^{2}$ University of KwaZulu-Natal, Durban, South Africa
}

Received: September 29, 2019

DOI: $10.5430 /$ jnep.v10n6p26
Accepted: December 11, 2019 Online Published: March 6, 2020

URL: https://doi.org/10.5430/jnep.v10n6p26

\begin{abstract}
Technological innovations such as e-learning are rapidly transforming the ways that institutions of higher education teach and students learn. In nursing education, e-learning offers opportunities to reach a great number of students, irrespective of time and space. In the context of Rwanda, the implementation of e-learning in nursing education was motivated by the country's need to upgrade the level of working nurses and midwives at a large scale and in a short period. This study aims at exploring the conceptualization of e-learning in nursing education, in the context of Rwanda. Grounded theory paradigm directed this study based on the Framework from Straus and Corbin (2008). The sample size was comprised of 40 participants: 18 nurse educators, 17 nursing students, two ICT managers, and three experts in the fields. The results indicated that e-learning was conceptualised as (a) a mechanism to advance a political agenda; (b) a tool to open access to education for working nurses and midwives; (c) a student-centred approach, (d) a blended learning.
\end{abstract}

Key Words: Conceptualization, E-learning, Nursing education, Technology, Rwanda

\section{BACKGROUND}

Technological innovations such as e-learning are rapidly transforming the ways that institutions of higher education teachers and students learn. ${ }^{[1-3]}$ Nursing education, like other sectors the technology, is used to respond to numerous challenges at local and international levels. ${ }^{[4-6]}$ These challenges include quality of education, shortage of nurses and midwives, an increasing number of students joining tertiary institutions, and empowering the significant number of working nurses with necessary skills. ${ }^{[5]}$

E-learning is regarded as the "use of electronic systems such as computers, internet and multimedia CDs" to enhance teaching and learning. ${ }^{[2,7]}$ According to Saba, ${ }^{[8]}$ e-learning systems are used to deliver instructions that can produce equal or better outcomes than face-to-face learning systems. Furthermore, it is used by institutions to improve and sup- port teaching while offering courses to a greater number of students around the world, ${ }^{[9]}$ and to improve learning outcomes. $^{[8,10]}$ The popularity of e-learning in education is associated to the flexibility to offer course content irrespective of the time and the location, promoting students' cantered approach, ability to train a significant number of student in a shot-time, and promoting collaboration between the learners and the instructors. ${ }^{[6,7,11]}$

E-Learning plays a vital role in the education of health professionals across the globe. ${ }^{[12,13]}$ According to Walsh, Bhagavatheeswaran, ${ }^{[13]}$ "e-learning is essentially about education, and it is also considered as a social phenomenon as part of the technological revolution" (p.1). Since 2000 there has been an explosion using technological innovations in teaching and learning such as online, e-learning, and blended learning. ${ }^{[14]}$ E-learning offers several benefits, and it includes teaching

\footnotetext{
*Correspondence: Alexis Harerimana; Email: haralexis@yahoo.fr; Address: James Cook University, College of Health Sciences, Townsville, Australia.
} 
and learning that is supported by information communication technologies, with the computers and internet being at the centre. This includes all the tasks performed out by individuals or people, and they are carried out synchronously or asynchronously, connected to the internet or not, and other ICT tools. ${ }^{[15-17]}$

It is crucial to ensure that the role of technology in nursing education is well understood, and preparing nursing students who are competent to work in a technology-driven health environment requires teaching institutions to integrate it effectively into their curriculum. ${ }^{[18,19]}$ Although e-learning is widely much-admired for its benefits, there are several issues associated to its implementation such as lack of knowledge and skills to use computers and internet, cultural and linguistic barriers, poor infrastructures and technical limitations. ${ }^{[5,7]}$

\section{Context of the study}

In the context of Rwanda, information communication technology is fundamental to Rwanda's Vision for 2020. [20-23] E-learning was introduced in Nursing Education in 2012, as a way of upgrading academic levels of working nurses from diploma (A2) to advanced diploma level (A1).

The nursing workforce in Rwanda consists mainly of nurses with diploma level. However, there is an increasing trend of training of nurses and Midwives with an advanced diploma, bachelor's degree, and master's degree. ${ }^{[24]}$ The critical shortage of health professionals has resulted in only $30 \%$ of health facilities being able to meet minimum staffing needs. ${ }^{[25]} \mathrm{A}$ significant factor contributing to the shortage of professional nurses is the insufficient number of qualified nursing faculty. ${ }^{[26,27]}$ In Rwanda, there is thus a significant need to educate, recruit, and retain nursing faculty. ${ }^{[27]}$ To effectively utilise innovative teaching strategies that promote competencies for nursing students. ${ }^{[27,28]}$ The implementation of e-learning in Rwanda was motivated by the needs to improve the quality of nursing, to train competent nurses and midwives who are capable of responding to the Health need of the Rwandan Population. ${ }^{[6,29]}$ This paper explores the understanding of e-learning in nursing education in the context of Rwanda.

\section{Methodology}

\subsection{Approach}

Grounded theory paradigm guided this study in order to analyse the utilisation of the e-learning platform and was guided by Straus and Corbin's framework. ${ }^{[30]}$

\subsection{Participants}

In this study, the participants were nurse educators, students, ICT managers, and campus manager of the three selected nursing school campuses where the e-learning platform was implemented. A non-probability, purposive sampling was applied by the researcher, based on the participants' involvement in teaching and learning through an e-learning platform, and who would provide useful information to the study. Theoretical sampling and data saturation guided the final number of participants. The sample size was comprised of 40 participants: 18 nurse educators, 17 nursing students, two ICT managers, and three experts in the fields (two in nursing education, and one in distance learning) who were recommended by the selected nursing school.

\subsection{Data collection}

In this study, data were collected through in-depth interviews, focus group discussion, and document analysis. All the participants were approached on their campuses, or in the areas where they were participating in academic-related activities (clinical settings for students) and at the National Council for Nurses and Midwives (NCNM) during the marking of the licensing examination, and the purposes of the study were fully explained, and consent obtained. The interviews were conducted by the researcher and were audio-recorded in a quiet and confidential place. The duration of the interviews was 20 to 40 minutes, with the interviewer using open-ended questions that participants were encouraged to discuss, and 40 minutes for the focus group discussions.

\subsection{Data analysis}

Data analysis was guided by Strauss and Corbin's framework of grounded theory. ${ }^{[30]}$ This consisted of 'analysing and interpreting data, to extract the meaning, understanding and develop empirical knowledge'. As recommended by Straus and Corbin ${ }^{[30]}$ data analysis was conducted through the process of coding. In the open coding, common themes of everyday life were identified and examined in relation to the context, meanings, and the utilisation of the e-learning platform in selected nursing campuses. Interviews were coded by conceptualising underlying patterns in the data. Initial data analysis guided further data collection, leading to further conceptualisation of the data and refinement of the coding schemes. Conceptual saturation was reached when no new categories were generated. Through the process of open coding, memos were written throughout the coding process to track conceptual decisions and ideas as they were occurring. In addition, memos were coded using theoretical coding. In order to facilitate the process, NVIVO 10 was used.

\subsection{Ethical clearance}

The study began after obtaining ethical clearance from the ethical committee from an educational institution in South Africa (HSS/1294/014D), and the Rwanda Ministry of Edu- 
cation (No 1637./12.00/2015). Permission was also obtained from the selected nursing school where the study was conducted. Data were collected from June 2015 to June 2016.

\section{Findings}

In this study, e-learning in nursing education was conceptualized as (i) a mechanism to advance a political agenda; (ii) a tool to open access to education for working nurses and midwives; (iii) a student-centred approach, (iv) a blended learning.

\subsection{E-learning as a mechanism to advance political agenda}

E-learning was conceived as a mechanism to advance the political agenda, and since 2000 , the government in Rwanda has put in place foundations and empowering environment for ICT development. ${ }^{[31]}$ There is a significant increase in the use of computers and internet in all sectors of life, with a strong emphasis on education. In health, there is a focus on addressing the shortage of specialised health personnel and improving the quality of healthcare and health policy, while continuing the successes of home-grown solutions like the integration of e-learning in nursing education. The Rwanda Ministry of Health is one of the aggressive users of technology and has initiated the transformation of the nursing and midwifery education through its 2012-2018 strategic plan, by upgrading nurses with A2 level (diploma) to nurses with A1 level. Part of this transformation e-learning was initiated in public nursing schools in Rwanda.

"There is a significant increase in the use of computers in public as well as private sectors. The culture of using computers is higher than ever before. ICT Capacity Building in the Public and Private Sector is aimed at encouraging the public and private sector to start using ICTs..."[32]

"Addressing the shortage of specialised health personnel and improving the quality of healthcare will be the focus of health policy while continuing the successes of home-grown solutions....,"[33]

“... Until 2012 ... more than $90 \%$ of the nurses have the lowest level of nursing training available (equivalent to secondary-school qualifications, or A2 level)... A1 nurses represent less than $10 \%$ of the total pool of nurses. A2 nurses are relatively evenly spread throughout the country, though there are still disparities between districts, with a number of under-served districts in the South, West and Northern Provinces. On average there is about 1 nurse for a population of $1,500 \ldots .,{ }^{[34]}$

"The e-learning program which started in January in 5 schools of nursing and midwifery (Kabgayi, Rwamagana,
Nyagatare, Kibungo and Byumba) [recruited students] from different health centres and hospitals with the aim of increasing quantity and quality of nurses in the country. The turn up for the first in-take included all heads of health centres countrywide and 12 nurses who still have A2 level [....] This blended mode of learning comprises of face-to-face contact sessions between students and their lecturers and distance learning in form of e-learning., "[35]

\subsection{E-learning as a tool to open access to education for working nurses and midwives}

E-learning was conceptualised as a tool to open access to education for working nurses and midwives. In this study, it was noted that diploma levels in nursing were replaced by advanced diploma levels with the aim to upgrade the academic levels of working nurses and to train competent nurses and midwives who are competent to respond the health problems of the country. Furthermore, there was the need to meet regional and international standards, through using innovative teaching strategies.

This study found that e-learning was used in nursing education as an urgent way of increasing nursing workforce, and this was due to the fact that traditional teaching methods were not meeting the job demands, and few numbers of the nursing institutions, both public and private were not able to accommodate those who needed to upgrade from diploma to advanced diploma without creating a gap in the working environment. E-learning initiative was launched in public nursing schools by the Ministry of Health in collaboration with Rwandan Human Resources for Health, and other stakeholders. The extracts below from participants' comments shows this:

"There is an initiative to upgrade nurses from A2 to A1, including the introduction of eLearning. The number of A1 nurses should see the most notable increase over the next few years, as A2 and A3 nurses are no longer trained in Rwanda."[36]

"E-learning was introduced in our institution to upgrade more nurses with diploma (A2) level to advanced diploma (A1) level in a short time..." (TP19)

"E-learning was initiated in schools of nursing and midwifery to upgrade the academic level of nurses with a diploma to an advanced diploma while they still work in their respective hospitals and health centres..." (TP20)

"It will benefit individual students because they will continue to work and earn salaries while studying; another advantage is that they will remain in their families and will also benefit healthcare facilities in terms of continuity of care."[35]

ISSN 1925-4040 E-ISSN 1925-4059 
“...e-learning is a good program because it helps many people in peripheral hospitals, health centres to increase their level of the study..." (SP13)

The choice of e-learning is based on the fact that it allows for flexibility of time and distance for teachers and learners. In this study, participants expressed that e-learning provides opportunities to use technology to get information remotely without being restricted by time (e.g. working hours of the library) or by distance (e.g. travelling to the library). E-learning provides options to search solely open-access resources. E-learning was reported to provide the opportunity to obtain a wider range of electronic resources, anytime and anywhere.

"Yeah, it reduces the time the students will be at school, by using the video teleconference..." (TP13)

"E-learning program will allow students to improve their knowledge through online resources" (TP7)

"E-learning is good in education because you have to search for information from different resources... " (TP3)

\subsection{E-learning as a student-centred approach}

E-learning was conceptualised in this study as a studentcentred approach. The findings indicated the following dimensions as characterising a student-centred approach in e-learning: (i) it promotes self-directed learning; (ii) it is collaborative; (iii) it is inquiry-based learning; (iv) it is interactive learning, and (v) it enables the integration of theory into practice.

\subsubsection{E-learning promotes self-directed learning}

E-learning was reported to encourage the students' autonomy, motivation and self-management. The participants reported that significant time is spent on self-directed learning which accounts. The participants said that they appreciated self-directed learning because they get more than what their facilitators should provide; it allows them to do other activities, and the teachers mentor, and give them constructive feedback when they meet difficulties while learning on their own. Another element that emerged was that participants viewed problems as challenges, and not obstacles, which they had to solve using their basic skills and experiences. It was noted as well that participants reported that self-directed learning provided the opportunity for students to learn of their own time and pace, and setting their own goals. Some of the participants explained how they enjoyed learning in self-directed learning as it helped them evaluate the achievement of their goals. Teachers shared the same view that e-learning can help them in self-directed learning in their free time, such as during the evening, and particularly when they are preparing their lessons as they have open access to information.

"When e-learning is used properly, it is exciting, it makes the student be self-directed... It lets the nurses learn from their hospitals while." (TP4)

“...currently self-directed learning is very much important... Students are given enough time to go and learn on their own, using technology... online they can find many resources, eBooks, and different journal articles." (TP17)

\subsubsection{E-learning promotes collaboration}

Data reflected that a student-centred approach promoted collaboration among the nursing students and their teachers. Data sources demonstrated that collaborative learning could occur in larger groups or peer-to-peer. Peer instructions or peer learning promotes the involvement of the students, either in pairs or small groups in activities that encourage discussions, and problem-solving. Similarly, in e-learning, this can be done through forum discussion, chatting, and communication with peers or teachers through emails or social networks.

In this study, the collaboration was reported to promote working together between students, teachers, ICT managers and administrative staff. Collaboration occurred through forum discussion on Moodle, e-mails, WhatsApp, Facebook and even during face-to-face interactions with their teachers or during group discussions with their peers. Collaboration promotes communication and exchange of information between the students and the teachers for academic purposes.

"I communicate with students through emails, and I chat with them on WhatsApp.” (TP1)

"We use the group work because if I fail to find the answers, other students can explain... or assist.” (SP3)

"We discuss with colleagues via group email, Facebook, and WhatsApp.” (SP5)

"When we are facilitating the students, we try to upload the contents, the quizzes... and so on. We create a forum discussion with the students... Also, I try ... to ask some questions and giving feedback." (TP18)

\subsubsection{E-learning promotes inquiry-based learning}

In this study, e-learning was reported to serve as a tool to enhance inquiry-based learning. Inquiry-based learning is learning by doing, developing reflective practice, and is problembased or project-based. It was also interpreted as a form of discovery, allowing the students to reflect, observe and explore, plan and predict and after that experiment and reflect. The findings indicated that through the research conducted on the internet, students obtained a variety of electronic resources, and were required to critically analysis them and 
decide on their usefulness. Furthermore, inquiry-based learning was enhanced through learning actives either performed through forum discussions on Moodle, and assignments.

"Students compare information from different sources when they are doing their assignments. They choose relevant information and from credible sources" (TP3)

"while using the Internet, you search and you retrieve more information. . but if you use the books it is very difficult to receive more information, or new information, or up-to-date information.” (SP7)

"Forum discussion and WhatsApp are used where students provide information related to a given task or respond to the questions from peers. As a teacher, you facilitate the process and let the students challenge their peers in their discussion, and intervene for clarification or addon..." (TP6)

\subsubsection{E-learning promotes interactive learning and active learning}

Data sources revealed that e-learning promotes purposeful exchange and challenge of ideas through the involvement of peers and teachers, and all students have equal right to contribute. Interactive learning allows students to be motivated and engaged in their studies. To enhance the students' attention, teachers reported using animated PowerPoint, videos, and pictures. In addition, online forum discussion and chat through social media platforms were used. Other teachers used case scenarios, participative group discussion, and brainstorming.

Involving actively students in their learning is essential to assist them in building their knowledge. Through e-learning, students actively participate in the learning process in partnership with teachers and other students. Students' contributions and challenges are respected by other students and the teacher. Active involvement is achieved through face-to-face and online interactions.

"to get the student attention, I use animated PowerPoint presentations, group discussion, and role-plays.” (TP17)

"When we are in the group we do the discussion, ... and the problem or the issues in the course are solved... and help us to memorise very well our courses." (SP4)

"Teachers use Moodle... they post some course outlines, they put assignments, and facilitate the forum discussion.” (TP4)

"I use my computer for learning or having some discussions, receiving some information on e-mails and Moodle platform." (SP11)

\subsubsection{E-learning promotes the integration of theory and practice}

Data sources indicated that e-learning allows the students to become agents of change by using evidence-based practices. The integration of theory and practice allows students provide care that is patient-centred while being critical thinkers, being creative and making a link between what they studied in the theory and clinical practice. In this study, students reported using the knowledge gained at school during contact sessions to change some malpractices in their respective hospitals and health centres. Furthermore, students bring in class the experience they have accumulated through many years of working and this pivotal to their learning as adults.

"e-learning is a good program in nursing because after face to face session they go back to their clinical settings. They practice what they have learnt. It is a kind of integration.... It also allows the students to make a link between what is taught and what is on the ground in their clinical settings..." (TP6)

"The interest in e-learning program is to participate... when you are at work... when you learn something you put it in action [...] we do the correct practice because we learn and we work." (SP1)

\subsection{E-learning as a blended learning}

In this study, e-learning was conceptualized as a blended learning that combines online and face-to-face learning. It was noted that e-learning was seen as a tool that uses ICT in teaching and learning, allowing access to resources at any time and anywhere; thus e-learning was cost-effective and time-saving. Face to face learning sessions counted 40 per cent of learning, while online learning was 60 per cent. Moodle was used as the learning management platform in e-learning. This form of learning was viewed by the students as ideal for them because it allowed them to study while they keep their work. Blended learning was reported to be flexible in terms of accessing information from search engines or Moodle, and engaging with the teachers either during face to face sessions or forum discussions. During face to face sessions, teachers reported using active teaching strategies which engage the students such as interactive teaching, participatory teaching and small group discussions. Moodle facilitated the online learning sessions, where electronic resources were made available for the students, and got actively involved in their learning through online forum discussions, chat. Furthermore, some quizzes and assignment were done through Moodle. Participants reported that blended learning allowed them to be familiar with the technology either in synchronous or asynchronous ways. 
"Students access Moodle platform to access learning materials and discuss with the teacher about some issues related to the course. Teachers also put announcement on Moodle platform." (TP7)

"As a teacher, I choose what content of the course will be taught online and face to face, and I do this for each chapter." (TP4)

“... we use different approaches which help students to work together such as forum discussion, group works. We also use lecturing, PowerPoint presentations and use videos to demonstrate some procedures" (TP2)

"In e-learning system... students' exams, assignments, continuous assessment test are done face to face and they have to be followed in their clinical practices, also face to face." (TP2)

"Students are put in small groups so that students may collaborate, particularly in the group assignment and demonstration." (TP6)

\section{Discussion}

E-learning in nursing education was conceptualised as a mechanism to advance political agenda, a tool to open access to education for the working nurses and midwives, a student-centred approach and a blended learning.

\subsection{E-learning as a mechanism to advance political agenda}

Government policies can influence the use of e-learning in the education of health professionals. ${ }^{[13]}$ In this study, data sources indicated that e-learning is conceived as a mechanism to advance the political agenda in the field of education, health and technology in the context of Rwanda. Since 2000, the government in Rwanda has put in place foundations and empowering environment for ICT development. Today, the existence of a conducive legal and regulatory framework, availability of proper infrastructure and a growing and innovative human resource base is further positioning Rwanda as a regional ICT hub. ${ }^{[31]}$

In Rwanda, a special focus on the health sector is on addressing the shortage of specialised health personnel and improving the quality of healthcare and health policy while continuing the successes of home-grown solutions like the community health workers model. The Rwanda Ministry of Health has adopted e-learning as an innovative strategy to upgrade nurses with diploma level to advanced diploma. ${ }^{[37]}$

Although Rwanda has made a significant effort in integrating ICT in education, emerging data showed that the country will continue to rely on imported technology from advanced

Published by Sciedu Press countries, and that well-trained, specialised nationals will be essential to the running and maintenance of technological systems. It is in line with this that the government has promoted partnership and collaboration with various stakeholders, and in particular US faculty, in order to introduce e-learning in nursing education. It emerged from this study that the partnership with US faculty in the field of nursing education has provided technological support, pedagogical support, financial support and research support. ${ }^{[29,33,38]}$ Walsh, Bhagavatheeswaran ${ }^{[13]}$ argue that taking into consideration political perspectives, e-learning should be aligned with the political healthcare goals and population need of the country. Furthermore, e-learning programmes should be planned inline to the undergraduate and postgraduate programmes and should be validated and accredited by the relevant national body.

\subsection{E-learning as a tool to open access to education for the working nurses and midwives}

E-learning was conceptualised as a tool to open access to education for working nurses and midwives. This was the initiative of the Rwandan Ministry of Health, in collaboration with other stakeholders, mainly Rwanda Human Resources for Health. In this study, it was noted that diploma levels in nursing were replaced by advanced diploma levels with the aim to upgrade the academic levels of working nurses and to train nurses and midwives who are competent to respond the health problems of the country.

Nurses are a significant component of the health workforce in Rwanda, but also that there was a need to increase the number of healthcare professionals by training more qualified nurses. ${ }^{[38]}$ E-learning was used in nursing education for an urgent increase in the supply of health workers since traditional classroom training in specific institutions had proven to be insufficient to accommodate all those with nursing diplomas obtained in the previous system of training. The new training program would address the critical shortage of qualified nurses in Rwanda, and result in improved health services, particularly in remote areas. ${ }^{[38,39]}$

A similar program was initiated in Tanzania for upgrading the qualification level of nurses from an enrolled nurse (EN) to registered nurse (RN) through distance/online learning. This is the EN-RN Conversion Diploma Programme, supported by the Aga Khan Development Network, that provided in Tanzania a distance learning program from 2006. This type of learning allows the students to use ICT tools in learning, and to interact with teachers who offer them the needed support. Integration of theory into practise is emphasised as students as the students use their acquired knowledge into their clinical practicum. ${ }^{[40]}$ 
The integration of e-learning in education is pivotal as it creates a new environment for teaching and learning in which rich content can be deployed easily, quickly and cheaply. It allows virtual communication among teachers and learners through e-mail, discussion forums, chats, audio/videoconference and instant messaging. ${ }^{[41-43]}$ The internet makes almost infinite worldwide resources available to learners. E-learning allows flexibility of time and distance for teachers and learners. ${ }^{[4,45]}$

The flexibility brought by e-learning allows access to numerous open-access online resources rather than just to subscription-based resources from database and eBook vendors. E-learning provides options to search solely for openaccess resources. ${ }^{[45-49]}$ This flexibility provides opportunities to use technology for remote access to information without being restricted by time (e.g. working hours of the library) or distance (e.g. travelling to the library).

\subsection{E-learning as a student-centred approach}

E-learning was conceptualized a student-centred approach that uses teaching strategies which put the student at the centre of his learning. It was reported that e-learning facilitates self-directed learning, collaborative learning, inquirybased learning, interactive learning and the integration of the theory into practice. Anderson, ${ }^{[50]}$ stated that adopting student-centred learning in a classroom helps the students to be actively involved in their learning, and matching their needs to the learning styles. ${ }^{[50,51]}$

E-learning promotes self-directed learning, and encourage the students to become autonomous and it is essential to use approaches that promote students' self-management, selfmonitoring and motivation. ${ }^{[52]}$ Through self-directed learning, students are the master of their own learning and use information from the teachers or other sources. ${ }^{[53]}$ The literature indicated that self-directed learning is a type of learning in which students are allowed to work on authentic problems and tasks of their own choice, and are provided with learning support relating to their problems. ${ }^{[54,55]}$

In this study, collaborative learning was important in studentcentred approaches used in e-learning. Study findings demonstrated that collaborative learning could occur in larger groups or peer-to-peer. Peer instructions or peer learning promotes the involvement of the students, either in pairs or small groups in activities that encourage discussions, and problem-solving. Similarly, in e-learning, this can be done through forum discussion, chatting, and communication with peers or teachers through emails or social networks. Garrison and Vaughan ${ }^{[56]}$ argue that working collaboratively through a number of learning tasks such as group works, and assign- ment encourages the students to take the ownership of their learning and engage in relevant problem-solving activities.

In e-learning, the student-centred approach was reported to promote inquiry-based learning where nursing students worked on learning tasks by searching for information from the internet using various databases and responding effectively to the learning activities. According to Garrison and Vaughan, ${ }^{[56]}$ an educational inquiry is a systematic process of defining relevant questions, searching for relevant information, formulating solutions, and applying those solutions.

Data from this study showed that e-learning serves as a tool to enhance inquiry-based learning. Because inquiry-based learning is learning by doing and develop reflective practice and is problem-based or project-based it is also interpreted as a form of discovery, allowing the students to reflect, observe and explore, plan and predict and after that experiment and reflect. ${ }^{[57]}$

The finding from this study indicated that e-learning, as introduced in nursing schools in Rwanda, allows the students to become agents of changes by using evidence-based practices. Ossiannilsson, Altinay ${ }^{[58]}$ argue that the use of online learning programmes are valuable to the learners, and these pedagogical innovations should be recognized as "change agents and facilitators in the transition for opening up to education, and transformation of traditional campus education to open online learning arena" (p.1), and which is essential to the equity of a long-life learning. ${ }^{[58]}$

E-learning was reported to facilitate the integration of theory and practice. E-learning helped students to correct malpractices, and participants also reported that they were able to put into practice what they learned in class. Using authentic cases for learning facilitated the integration of theory and practice and assisted them in developing critical thinking and clinical problem solving, and nurturing a culture of patient-centred care. ${ }^{[59]}$ Mather and Cummings ${ }^{[60]}$ state that the integration of innovative technologies in healthcare settings has allowed the development of patient-centred care approaches. A study by Dhlamini ${ }^{[61]}$ on how the integration of theory and practice in nursing education is perceived by students and nurse educators found that the use of case studies and clinical scenarios which emirates the real life is important to teaching and learning which allows reflections on theory in relation to the practical experiences and vice versa. $^{[61]}$

\subsection{E-learning as a blended learning}

In this study e-learning was conceptualized as a blended learning that uses both online and face-to-face teaching and learning. The literature indicates that blended learning is 
being increasingly used in nursing education, ${ }^{[62,63]}$ and this is because this model allows offering course contents to more students than using traditional approach alone. ${ }^{[64]}$

Through online teaching and learning emphasis is placed on student interaction with faculty and other students. This is 'an essential characteristic and is facilitated through a variety of ways, including voice-mail and e-mail. Feedback on student assignments and questions is constructive and is provided in a timely manner. Students are instructed in the proper methods of effective research, including assessment of the validity of resources. For online teaching and learning to be effective, course development benchmarks should be considered. This includes the use of guidelines regarding minimum standards for course development, design and delivery, and determining the technology being used to deliver course content. Instructional materials are reviewed periodically to ensure they meet program standards. ${ }^{[63]}$

In blended learning, face-to-face teaching and learning sessions allow nursing students to maintain a connection to the campus and their peers and promotes a stronger studentinstructor connection. Though the face-to-face part of elearning, nursing students and teachers create social interaction through group collaboration to facilitate high achievement, promote verbal and nonverbal communication. ${ }^{[63]}$ The teaching sessions are done in real-time and with specific time frames for discussions, and assessment; and active teaching strategies are used. ${ }^{[65,66]}$ In the education of health professionals, active teaching strategies include case studies, problem-based learning, group work, group assignments, student presentations, demonstrations, brainstorming, and use of videos. ${ }^{[66]}$

Due to the importance attached to e-learning in the context of Rwanda, it is very crucial that technology is integrated into the undergraduate nursing curriculum, and not only focusing on basic computers but to expand it to nursing informatics. According to Coorey ${ }^{[67]}$ technology has been taught in isolation without direct applicability to the real context. Putting in place adequate pedagogical designs that combine technology, teaching strategies and learning styles across the undergraduate modules is recommended. ${ }^{[67]}$

\section{Conclusion}

E-learning is an essential approach in nursing education, as it creates a new environment for teaching and learning where rich content can be deployed easily, quickly and cheaply. Political commitment, country's ICT policies and availability of adequate infrastructures are pivotal to success and future sustainability of e-learning in education. The flexibility of time and distance brought by e-learning facilitate the training of a significant number of nurses considering the country's needs, and to improve the knowledge and the skills of working nurses. The use of blended learning where both face-toface and online teaching and learning are used, improve the learning outcomes by overcoming the challenges associated with traditional teaching approaches which put students in a passive mode. Thus, the use of technology to promote student-centred teaching strategies which facilitate students' self-directed learning, collaboration and active learning is highly recommended. Taking into consideration the way e-learning is understood in the context of Rwanda, and it is recommended that adequate pedagogical and technological designs be put in place. Basic computer skills and advanced informatics in nursing need to be integrated into undergraduate nursing curriculum, in order to produce competent graduates who are capable of working in a technology-dominated health sector.

\section{Conflicts of InTERest Disclosure}

The authors declare that there is no conflict of interest.

\section{REFERENCES}

[1] Nagarajan P, Jiji GW. Online educational system (e-learning). International Journal Of U-\& E-Service, Science \& Technology. 2010; 3(4): 37-48.

[2] Kok A. How to Manage the Inclusion of E-Learning in Learning Strategy: Insights from a Turkish Banking Institution. International Journal of Advanced Corporate Learning (iJAC). 2013; 6(1): 20-7. https://doi.org/10.3991/ijac.v6i1. 2341

[3] Al-Samarraie H, Teng BK, Alzahrani AI, et al. E-learning continuance satisfaction in higher education: a unified perspective from instructors and students. Studies in Higher Education. 2018; 43(11): 2003-19. https : //doi.org/10 .1080/03075079.2017.129808 8

[4] Msomi AP, Munapo E, Choga I. The conceptualisation of e-Learning in the public sector. Problems and Perspectives in Management 2016; 14(4): 41-53. https://doi.org/10.21511/ppm.14(4).2 016.05

[5] Harerimana A, Mtshali NG, Ewing H, et al. E-Learning in Nursing Education in Rwanda: Benefits and Challenges. An Exploration of Participants' Perceptives. Iosr Journal Of Nursing And Health Science. 2016; 5(2): 64-92.

[6] Harerimana A, Mtshali NG. Facilitation strategies used in e-learning by nurse educators in Rwanda. Journal of Nursing Education and Practice. 2017; 8(1): 24-32. https://doi.org/10.5430/jnep.v $8 \mathrm{n} 1 \mathrm{p} 24$

[7] Mohammadi N, Ghorbani V, Hamidi F. Effects of e-learning on language learning. Procedia Computer Science. 2011; 3: 464-8. https://doi.org/10.1016/j.procs.2010.12.078 
[8] Saba T. Implications of E-learning systems and self-efficiency on students outcomes: a model approach. Human-Centric Computing and Information Sciences. 2012; 2(1): 6. https://doi.org/10.1 186/2192-1962-2-6

[9] Benta D, Bologa G, Dzitac S, et al. University level learning and teaching via e-learning platforms. Procedia Computer Science. 2015; 55: 1366-73. https://doi.org/10.1016/j.procs. 2015.07. 123

[10] Donkin R, Askew E. An Evaluation of Formative "In-Class" versus "E-Learning" Activities to Benefit Student Learning Outcomes in Biomedical Sciences. Journal of Biomedical Education. 2017; 2017. https ://doi.org/10.1155/2017/9127978

[11] Lee S, Lee H, Kim T. A Study on the Instructor Role in Dealing with Mixed Contents: How It Affects Learner Satisfaction and Retention in e-Learning. Sustainability. 2018; 10(3): 850. https: //doi.org/10.3390/su10030850

[12] Neville V, Lam M, Gordon CJ. The impact of eLearning on health professional educators' attitudes to information and communication technology. Journal of Multidisciplinary Healthcare. 2015; 8: 75. PMid:25678796

[13] Walsh K, Bhagavatheeswaran L, Roma E. E-learning in healthcare professional education: an analysis of political, economic, social, technological, legal and environmental (PESTLE) factors. MedEdPublish. 2019; 8. https ://doi .org/10.15694/mep. 2019.0000 97.1

[14] Hogan R, Kedrayate A. E-learning: A survival strategy for developing countries. Social And Economic Studies. 2011; 60(3/4): 1-17.

[15] Naidu S. E-Learning: A Guidebook of Principles, Procedures and Practices. Melbourne, Victoria, Australia: Common Wealth Educational Media Centre for Asia (CEMCA); 2006.

[16] Baliya JN. Learner centered instructional design for e-learning content. International Journal Of Behavioral Social And Movement Sciences. 2012; 1(3): 194-201.

[17] Hadullo K, Oboko R, Omwenga E. Factors affecting asynchronous e-learning quality in developing countries university settings. International Journal of Education and Development using ICT. 2018; 14(1).

[18] Edwards J, O'Connor PA. Improving Technological Competency in Nursing Students: The Passport Project. Journal of Educators Online. 2011; 8(2): 1-20. https://doi.org/10.9743/JE0.2011.2.2

[19] Schwendimann R, Fierz K, Spichiger E, et al. A master of nursing science curriculum revision for the 21st century-a progress report. BMC Medical Education. 2019; 19(1): 135. PMid:31068167 https://doi.org/10.1186/s12909-019-1588-9

[20] Hennessy S, Onguko B, Harrison D, et al. Developing the Use of Information and Communication Technology to Enhance Teaching and Learning in East African Schools: Review of the Literature. UK: Centre for Commonwealth Education and Aga Khan University Institute for Educational Development - Eastern Africa; 2010.

[21] Farrell G. ICT in Education in Rwanda: Survey of ICT and education in Africa, Rwanda Country Report 2007 [cited 201310 September] Available from: http://www.infodev.org/infodev-files/r esource/InfodevDocuments_353.pdf

[22] Rubagiza J, Were E, Sutherland R. Introducing ICT into schools in Rwanda: Educational challenges and opportunities. International Journal Of Educational Development. 2011; 31(1): 37-43. https://doi.org/10.1016/j.ijedudev.2010.06.004

[23] Republic of Rwanda. Rwanda Vision 2020. Kigali: Republic of Rwanda; 2012. Available from: http://www.rsb.gov.rw/ rbs/fileadmin/user_uplo ad/files/Vision_2020_Booklet.pdf
[24] Anatole M, Magge H, Redditt V, et al. Nurse mentorship to improve the quality of health care delivery in rural Rwanda. Nursing Outlook. 2013; 61(3): 137-44. PMid:23164530 https://doi.org/10.101 6/j.outlook.2012.10.003

[25] Africa Health Workforce Observatory (AHWO). Human resources for health country profile: Rwanda 2009 [cited 2014 13th August]. Available from: http://www.hrh-observatory . afro.who.int/images /Document_Center/rwanda_hrh_countryprofile.pdf

[26] Rukholm EE, Stamler LL, Talbot LR, et al. Scaling up the global nursing health workforce: Contributions of an international organization. Collegian. 2009; 16(1): 41-5. PMid:19388426 https : //doi.org/10.1016/j.colegn.2009.01.001

[27] Thuss ME. Nursing clinical instructor experiences of empowerment in Rwanda: applying Kanter's and Spreitzer's theories [Dissertation]. London, Ontario, Canada: Western University; 2014.

[28] Harerimana A, De Beer J. Nurse educators' utilisation of different teaching strategies in a competency-based approach in Rwanda. Africa Journal Of Nursing And M Dwifery. 2013; 15(1): 29-41.

[29] Mukamana D, Uwiyeze G, Sliney A. Nursing and midwifery education in Rwanda: Telling our story. Rwanda Journal. 2015; 2(2): 9-12. https://doi .org/10.4314/rj.v2i2.1F

[30] Strauss A, Corbin J. Basics of Qualitative Research: Grounded Theory Procedures and Techniques. Newbury Park: Sage; 1990.

[31] Republic of Rwanda. National ICT Strategy and Plan NICI - 2015. Kigali: Republic of Rwanda; 2015.

[32] Republic of Rwanda. DRAFT (1st Physical Meeting): WSIS+10: Overall Review of The Implementation of the WSIS Outcomes 2015 [cited 2016 16th March]. Available from: https://www.itu.int/net/wsis/review/inc/docs/r creports/WSIS10_Country_Reporting-RWA.pdf

[33] Republic of Rwanda. Rwanda Vision 2020: Revised 2012. Kigali: Republic of Rwanda; 2012. Available from: http://www.minecofin.gov.rw/fileadmin/templates/d ocuments/NDPR/Vision_2020_.pdf

[34] Ministry of Health of the Republic of Rwanda (MOH), Human Resource for Health (HRH). Human Resources for Health Program. Strategic plan 2011-2016 Kigali: Mininistry pf Health; 2011 [cited 2015 10th December]. Available from: http://www. brown.edu/ academics/medical/bright/sites/browncedu.academics .medical.bright/files/uploads/MOH $\% 20$ Rwanda $\% 20 \mathrm{HRH} \% 2$ OStrategic\%20Plan $\% 202011 \% 20-\% 202016$.pdf

[35] Rwanda Biomedical Centre (RBC). E-learning program to promote the quality of nursing and midwifery health services in Rwanda n.d [cited 2015 10th December]. Available from: http://rbc.gov.rw /spip.php?article292

[36] Rwanda Ministry of Health, Rwanda Human Resource for Health. Human Resources for Health Program. Strategic plan 2011-2016 Kigali: Mininistry pf Health; 2011 [cited 2015 10th December] Available from: http://www.brown.edu/academics/medical/ bright/sites/browncedu. academics .medical.bright/fi les/uploads/MOH $\% 20$ Rwanda $\% 20 H R H \% 20$ Strategic $\% 20 \mathrm{Plan} \%$ $202011 \% 20-\% 202016$.pdf

[37] Rwanda Ministry of Health. Third Health Sector Strategic Plan July 2012 - June 2018. Kigali: Mnistry of Health; 2012.

[38] Rwanda HRH. Rwanda Human Resources for Health Program, 2011-2019: Funding Proposal Part I 2011 [cited 201512 December 2015]. Available from: https://medicine.yale.edu/intmed/global/sites/Rwan da\%20HRH\%20Proposal\%20FINAL_129987_284_7289.pdf

[39] Binagwaho A, Kyamanywa P, Farmer PE, et al. The Human Resources for Health Program in Rwanda: A New Partnership. The 
New England Journal O F Medicine. 2013; 21(369): 2054-9. PMid:24256385 https://doi.org/10.1056/NEJMsr1302176

[40] Aga Khan Development Network. Upgrading Nursing Studies: Strengthening the Health-Care System in Tanzania 2007 [cited 2016 20th January]. Available from: www .akdn.org/publications $/ 20$ 07_akf_tanzania_nursing.pdf

[41] Khan BH. Managing E-Learning: Design, Delivery, Implementation, and Evaluation. London: Information Science Publishing; 2005.

[42] Kim J. Influence of group size on students' participation in online discussion forums. Computers \& Education. 2013; 62: 123-9. https://doi .org/10.1016/j. compedu .2012.10.025

[43] Ferschke O, Howley I, Tomar G, et al. Fostering Discussion across Communication Media in Massive Open Online Courses. Proceedings Of The 11th International Conference On Computer Supported Collaborative Learning; Gothenburgh, Sweden. 2015.

[44] O'Lawrence H. An overview of the influences of distance learning on adult learners. Journal Of Education And Human Development. 2007; 1(1): 1-8.

[45] Dalhem WA, Saleh N. The impact of eLearning on nurses' professional knowledge and practice in HMC 2014 [cited 2016 14th May]. Available from: http: //search.proquest. com/openview/2e129e5ef3b3c6e6b00 b1010dd2a25e4/1?pq-origsite $=$ gs cholar\&cbl $=2026675$

[46] David O, Salleh M, Iahad N. The impact of e-learning in workplace: Focus on organizations and healthcare environments. Int Arab J ETechnol. 2012; 2(4): 203-9.

[47] Brown J, Denny B, Butler MM, et al. Sharing Online Educational Resources, Platforms and Practices for E-Learning/m-learning in GP Registrar Education (GEM). Australia: Southern GP Training \& RMIT University; 2014.

[48] Mills R, Tait A. The Convergence of Distance and Conventional Education: Patterns of Flexibility for the Individual Learner. London: Routledge; 2002.

[49] McVeigh H. Factors influencing the utilisation of e-learning in postregistration nursing students. Nurse Education Today. 2009; 29(1): 91-9. PMid:18774625 https://doi.org/10.1016/j. nedt. 200 8.07 .004

[50] Anderson J. ICT Transforming Education. Bankock, Thailand: UNESCO; 2010.

[51] Oliveira GP, Aarreniemi-Jokipelto P, Boaventura RS. Significant changes in the environment and in teaching methodology of an elearning discipline to avoid dropouts in a course at the federal institute. 12th International Conference On Cognition And Exploratory Learning In Digital Age (Celda 2015); Federal Institute of Triangulo Mineiro - IFTM: Brazil. 2015.

[52] Dawson S, Macfadyen L, Risko EF, Foulsham T, Kingstone A. Using technology to encourage self-directed learning: The Collaborative Lecture Annotation System (CLAS). 2012.

[53] Suknaisith A. The results of self-directed learning for project evaluation skills of undergraduate students. Procedia-Social and Behavioral Sciences. 2014; 116: 1676-82. https ://doi.org/10.1016/j.sb spro.2014.01.455

[54] Dawson S, Macfadyen L, Evan FR, et al. Using technology to encourage self-directed learning: The Collaborative
Lecture Annotation System (CLAS). Australasian Society For Computers In Learning In Tertiatry Education [Internet]. 2012 20th January 2016. Available from: http: //www.ascilite.org/conferences/Wellington12/2012/i mages/custom/dawson,_shane_-_using_technology.pdf

[55] Saxena S. How Technology Supports Self-Directed Learning 2013 [cited 2016 20th January]. Available from: http://edtechreview.in/news/824-how-technolog y-supports-self-directed-learning

[56] Garrison DR, Vaughan ND. Blended Learning in Higher Education: Framework, Principles, and Guidelines. New Jersey: John Wiley \& Sons; 2008. https://doi .org/10.1002/9781118269558

[57] Vaughan N. Designing for an inquiry based approach to blended and online learning. Revista Eletrônica de Educação. 2015; 9(3): 30-47. https://doi.org/10.14244/198271991382

[58] Ossiannilsson E, Altinay F, Altinay Z. MOOCs as change agents to boost innovation in higher education learning arenas. Education Sciences. 2016; 6(3): 25. https://doi.org/10.3390/educsci6 030025

[59] Harerimana A, Mtshali NG, Ewing H, et al. E-Learning in Nursing Education in Rwanda: Benefits and Challenges. An Exploration of Participants' Perceptives. IOSR Journal of Nursing and Health Science. 2016; 5(2): 64-92.

[60] Mather C, Cummings E. Empowering learners: Using a triad model to promote eHealth literacy and transform learning at point of care. Knowledge Management \& E-Learning: An International Journal (Km\&El). 2015; 7(4): 629-45. https://doi.org/10.34105/j.k mel.2015.07.041

[61] Dlamni C. Perceptions of students and nurse educators on the integration of theory and practice in nursing education in Swaziland: An exploratorydescriptive study [Dissertation]: University of KwaZulu Natal; 2011.

[62] Hee-Jung J, Sun-Yeun H. The Effects of Blended Learning in Nursing Education on Critical Thinking and Learning Satisfaction of Nursing Students. Ad Sc Technol Lett. 2016;122.

[63] Protsiv M, Rosales-Klintz S, Bwanga F, et al. Blended learning across universities in a South-North-South collaboration: a case study. Health Research Policy and Systems. 2016; 14(1): 67. PMid:2758996 https ://doi .org/10.1186/s12961-016-013 $6-\mathrm{x}$

[64] Atkins S, Yan W, Meragia E, et al. Student experiences of participating in five collaborative blended learning courses in Africa and Asia: a survey. Global Health Action. 2016; 9(1): 28145. PMid:27725077 https://doi.org/10.3402/gha.v9.28145

[65] Vincent P, Pilotti M, Hardy P. An exploratory study on instructor conduct and characteristics in the online classroom as predictors of student participation. Comprehensive Psychology. 2016; 5: 1-12. https://doi.org/10.1177/2165222816646236

[66] AlRuthia Y, Alhawas S, Alodaibi F, et al. The use of active learning strategies in healthcare colleges in the Middle East. BMC Medical Education. 2019; 19(1): 143. PMid:31088430 https://doi.org/ 10.1186/s12909-019-1580-4

[67] Coorey J. Active learning methods and technology: Strategies for design education. International Journal of Art \& Design Education. 2016; 35(3): 337-47. https://doi.org/10.1111/jade. 12112 